\title{
In Memory of Claudio Ferdinando Donner
}

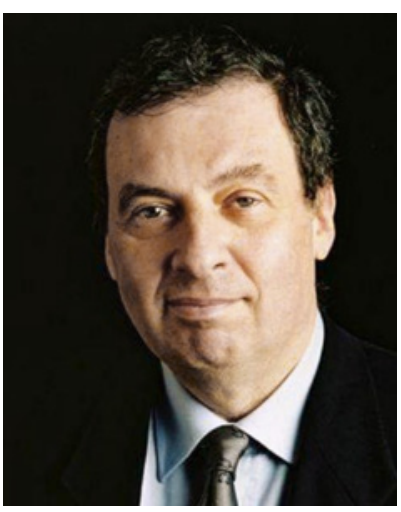

Claudio Ferdinando Donner

Starting from the death of Claudio Ferdinando Donner, who died prematurely at the age of 72 , we can muse over the developments in the field of Pulmonology in Italy over the past 40 years.

In the early 1980s, at the time of my graduation, Pulmonology was taking its first steps from the parent specialty of Phthisiology. It was still a young specialty, which had to release itself from the fetters of the Tuberculosis "brand" to find its space and field of action.

Many pulmonologists were the actors of this revolution or better evolution of our specialty, contributing new ideas, confronting and, at times, even clashing with other medical fields (infectious diseases, allergology, oncology, etc.). Claudio was undoubtedly one such key figure.
There was an absolute need to modernize Pulmonology by giving it a broader perspective, taking into account the international scene, designing new paths, making use of new technologies, and recruiting the most enterprising young people who were willing to face the challenge of a new frontier.

His professional career bears witness to these trends, this evolution.

Hence, along with others, he was certainly a great innovator and modernizer of Italian Pulmonology.

Indeed, his role in this process has been acknowledged at all levels.

He created what I call a "dream team" at the Maugeri Institutes in Veruno, a group of colleagues with diversified specializations (i.e., re-training, ventilation, quality of life, sleep, biology, intensive care, etc.). Together with other leading institutes and clinical centers, their work led to the recognition of Pulmonary Rehabilitation as an integral and important part of Pulmonology.

In Italy, Claudio was at the top of Pulmonology and a key opinion leader both for the various scientific societies (primarily AIPO but not only) and in a transversal and inter-societal way.

Claudio was one of the best known and most appreciated Italian Pulmonologists on the international scene. He held high-ranking corporate roles both in Europe (among other things, he was Secretary General of the ERS for 6 years) and in America. 
From a scientific perspective, today PubMed lists more than 200 scientific papers published by him in international journals, touching all fields of Pulmonology and of Medicine.

Claudio also possessed the unique ability of converging the various specialists in Pulmonology, both in Italy and abroad, without distinction of roles, affiliations, or particular attitudes. In addition to this, once again acting as a forerunner, he always paid particular attention to patient associations. It is no mere chance that he was one of the main promoters, if not the key promoter, of an initiative launched in the pre-COVID era (La Consulta della Pneumologia) that brought together scientific and professional associations, non-profit organizations, and associations of pulmonology patients to create a critical mass and give impetus to the world of respiratory diseases.

Each of his initiatives was inclusive and represented an opportunity to collaborate and achieve common objectives that would otherwise have been hard to reach.
A typical example can be found in the Conferences he organized. Some of them were truly memorable, not only for the locations but especially for the quality of their content, which mirrored the exceptional standard of the speakers, who were leaders in their discipline. The documents and congress proceedings resulting from such events are still a valuable landmark for the sector today.

I personally owe a lot to Claudio who wanted me to join him in Veruno many years ago, offering me the opportunity to grow in a fertile and productive environment, together with other colleagues who are also leading Pulmonologists.

However, considering all the above, I do not think I am wrong in saying that Italian Pulmonology owes a lot to Claudio.

We shall miss him very much.

Once again, condolences and a warm hug to his family, Franca, Mirella, and Valentina.

Bruno Balbi, Veruno (Novara) 